\title{
Working
}

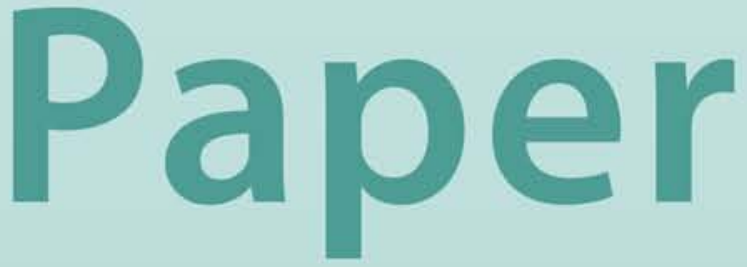




\title{
Poverty, Inequality, and Unethical Behavior of the Strong
}

\author{
Arye L. Hillman
}




\title{
IMF Working Paper
}

Fiscal Affairs Department

\section{Poverty, Inequality, and Unethical Behavior of the Strong}

\author{
Prepared by Arye L. Hillman ${ }^{1}$ \\ Authorized for distribution by Sanjeev Gupta
}

November 2000

\begin{abstract}
The views expressed in this Working Paper are those of the author(s) and do not necessarily represent those of the IMF or IMF policy. Working Papers describe research in progress by the author(s) and are published to elicit comments and to further debate.
\end{abstract}

This paper is concerned with economic consequences of unethical governance. A framework is set out, based on principles of Friedrich Nietzsche, that ties poverty and inequality to unethical behavior of the strong toward the weak. The paper contributes to an understanding of why poverty and inequality have remained entrenched in some societies in spite of repeated programs intended to improve living standards. The purpose is to include ethics of governance, and, in particular, unethical behavior of the strong toward the weak, in preconditions for economic development.

JEL Classification Numbers: I3, O1, H1

Keywords: poverty, development, government, ethics, Nietzsche

Author's E-Mail Address: hillman@mail.biu.ac.il

${ }^{1}$ The author benefited from the observations of Roger Congleton, Richard Disney, Sanjeev Gupta, Gil Epstein, Carsten Hefeker, Michael Leidy, Branko Milanovic, Piroska Nagy, Ngo Van Long, Charles Rowley, Maurice Schiff, Peter Birch Sørensen, Vito Tanzi, Günther Taube, and Heinrich Ursprung. The author thanks Vito Tanzi and the Fiscal Affairs Department of the International Monetary Fund for the opportunity to set out his ideas in the paper. 
I. Introduction

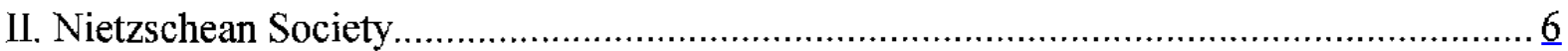

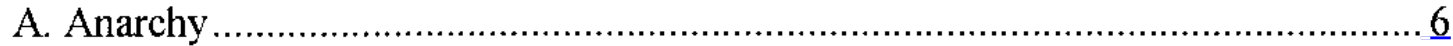

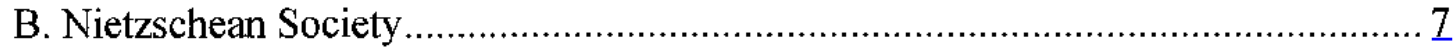

C. Mixed-Strategy Equilibrium .......................................................................... 2

D. Interpretation of the Equilibrium in Terms of Risk ........................................... 10

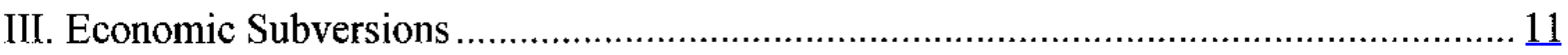

A. Adverse Consequences of Greater Productiveness ...........................................11

B. Subterfuge and Parasites ................................................................................. 12

IV. The Unequal Burden of Social Inefficiency …….................................................... 13

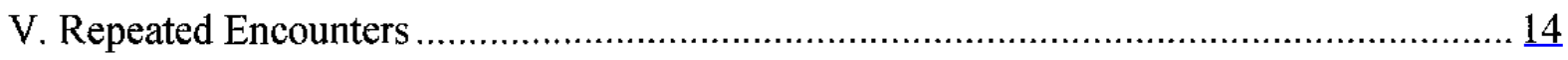

VI. Self-Interest of the Strong in the Rights of the Weak? …….................................... 15

A. Democracy and Majority Voting ……………………............................... 16

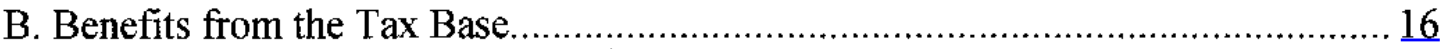

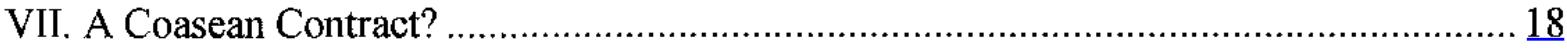

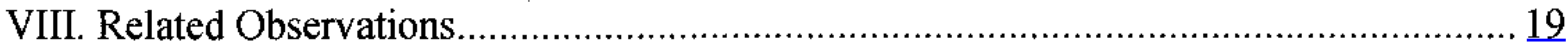

A. The Source of Advantage of the Strong ........................................................ 19

B. Enslavement and Disrespect for Life ..........................................................19

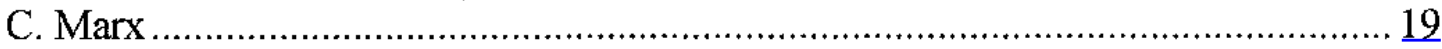

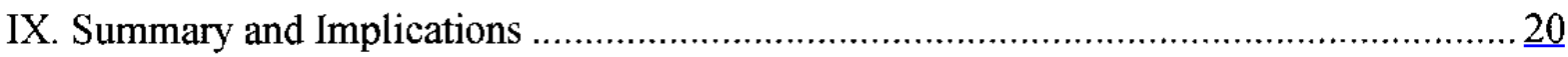

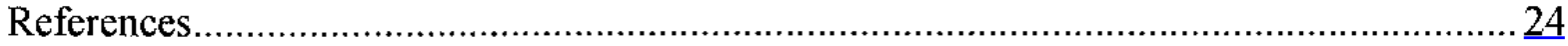

\section{Text Tables}

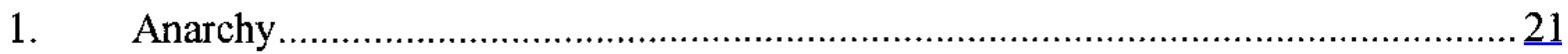

2. The Nietzschian Game .............................................................................. 21

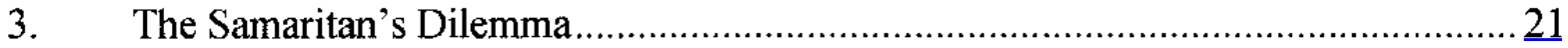

Figures

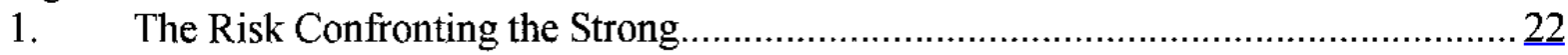

2. The Risk Confronting the Weak ......................................................................22

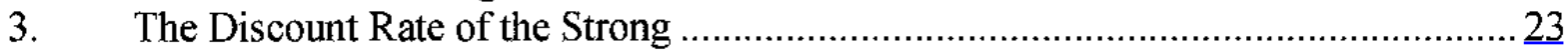


"There is a particular obviousness, almost a tautology, about the links between powerlessness and poverty. What is most important is clear and well known, and yet so discomforting for the powerful that we continue somehow to overlook it and talk about other things."

Robert Chambers (1983, p. 131)

"...if we learn anything from the history of economic development, it is that culture makes a difference."

David Landes (1998, p. 516)

\section{INTRODUCTION}

Broad poverty persisted in many societies in the second half of the twentieth century. ${ }^{2}$ Poverty remained entrenched, in spite of the resources, technical advice, and intentions of donors and agencies that sought to promote economic development.

Where poverty persists, the domestic distribution of wealth and income is also in general unequal. ${ }^{3}$ Vast segments of the population are extremely poor, and often a small part of the population has wealth that far exceeds that of the median or average person in the developed world.

This paper is concerned with the preconditions for ending poverty and extreme inequality. The focus is on ethics in governance. A framework based on the principles of the philosopher Friedrich Nietzsche (1844-1900) is used to examine the relationship between unethical governance and the persistence of poverty and inequality.

Ethics in governance complements other influences that can affect poverty and inequality. For example, the wealth of a society is sometimes explained with reference to natural resources, ${ }^{4}$ geographic location, ${ }^{5}$ and climate. ${ }^{6}$ Social norms also influence poverty and

\footnotetext{
${ }^{2}$ On corresponding international disparities in productiveness, see Hall and Jones (1999).

${ }^{3}$ See Chu, Davoodi, and Gupta (2000).

${ }^{4}$ Natural resources can also be an impediment to development when a society is preoccupied with contesting claims of ownership. See Gelb, Hillman, and Ursprung (1998).

${ }^{5}$ See Gallup, Sachs, and Mellinger (1998), Krugman (1998). In prehistoric times, attributes of local wild grasses and plants and availability of animals for domestication determined whether and when societies could change from being hunter-gatherers to sedentary farmers (see Diamond 1997).

${ }^{6}$ Climate influences health; under unfavorable conditions bacteria and parasites take up residence in the human body and erode the will and ability of people to produce, through adverse effects on health and physical strength.
} 
inequality, for example, through attitudes toward the education of children and the participation of women in market activity. ${ }^{7}$ Political economy perspectives also explain the incidence of poverty and inequality. ${ }^{8}$

The political-economy explanations emphasize the influence on governance of a society's collective decision-making institutions and political culture. Societies are poorer and income distribution is more unequal when contests for political office are tantamount to quests for personal gain and privilege, and when political success assumes the right or, perhaps the obligation, to bestow favors on family, friends, or affiliated groups. Intimidation and violence can also be part of the contest for the exercise of political authority for private gain. When political authority has been attained, the motive of private gain through government service is reflected in corruption. ${ }^{9}$

There are ethical values implicit in these observations on how political authority is attained and exercised. These ethical values are reflected in the limits placed on the acceptable means of attaining the authority to govern, and in the recognition that corruption in the exercise of government authority is a violation of public trust.

The Nietzschean behavior with which this paper is concerned is a retreat from ethical values. The behavior is not predicated on the good and the bad, but only on the strong and the weak. The strong seek their self-interest without inhibitions of conscience, while the weak have no means of resistance.

Nietzschean behavior contradicts a code of ethics set out some three and a half millennia ago that decreed that obstacles should not be placed before the blind-not only the physically blind. Strangers were not to be oppressed-the stranger being the weakest in a society, without ties to family or friends for defense. The right to life was to be respected, as also was the personal right to freedom and liberty — not to steal referred to stealing a person. The right of personal possession was protected in the injunction that one should not even contemplate appropriating the property of others. The rule of law was decreed to apply equally to all people, with no distinction between strong and weak.

Nietzsche, in contrast, viewed the imposition of the will of the strong over the weak as an inevitable consequence of nature (see, e.g., Nietzche's Beyond Good and Evil [1887], 1997). Thus, if the hawk takes delight in eating the lamb, and if the hawk has the means to prey upon and eat the lamb, then this is what the hawk will naturally do. The lamb can be

\footnotetext{
${ }^{7}$ On the role of norms in economic development, see for example Eggertsson (forthcoming).

${ }^{8}$ See Tanzi, Chu, and Gupta (1999) and Tanzi (2000).

${ }^{9}$ See Treisman (2000) on the scope of corruption. The effects of institutions and political culture on economic development and income inequality are supplemented by a proposed converse relationship through incentives for redistributive activities; see Milanovic (2000) for an empirical study and reference to previous literature.
} 
predicted, according to Nietzsche, to intellectualize its plight and to develop a moral philosophy that presents the lamb as good and the hawks as bad because lamb do not kill and eat hawks. For Nietzsche, however, the behavior of the hawk follows from the hawk being strong and the lamb being weak. The hawk is but acting out its role in the way that nature allows. The lambs may plead for ethical behavior and may make appeals to conscience, but this is no more than the defense of the weak against the natural superiority of the strong.

Nietzschean behavior has given rise to acts of extreme inhumanity. This paper is not about past inhumanity, ${ }^{10}$ but about behavior in the more contemporary circumstances of poverty and inequality.

In this respect, we can be guided by Robert Chamber's (1983) description of conditions in poor societies. Chambers used evidence from case studies to identify three means whereby the strong act unethically toward the weak: the strong "stand as nets between the poorer people and the outside world, by the sense that they catch and trap resources and benefits;" the strong take from the weak by "outright robbery"; and the strong appropriate from the weak by pre-empting competition that would allow the weak to obtain the market-determined value of their output (pp. 131-138).

The circumstances described by Chambers changed in the last two decades of the twentieth century, but not everywhere. Nietzschean attributes can, for example, be seen in the "strong men" syndrome in sub-Saharan Africa (see Charles Rowley, 2000), and in parts of Latin America and Southeast Asia where selected families control economic domains and contain efforts at liberalization and economic reform that would benefit the broad population (see for example the case study of Indonesia by Cassing, 2000). The caste system in India is another case of unethical behavior of the strong toward the weak. Unethical behavior of the strong toward the weak has also been observed in the transition societies (see Havrylyshyn, 1995, Levin and Satarov (2000)).

Judgments can be made on whether the political culture of a society is good or bad (see Hillman and Swank, 2000), and Nietzschean political culture is clearly bad by being unethical. The intention here is not, however, to pass judgment based on ethics. The purpose is, rather, to examine the economic consequences of the unethical exercise of authority.

Societies where the strong behave unethically can be shown to be inefficient and the costs of these inefficiencies are borne exclusively by the weak. The strong have no personal incentive to respond to proposals for programs to correct the inefficiencies. Policy advice is therefore ineffective.

\footnotetext{
${ }^{10}$ Bernholz (1993) interprets past inhumane behavior in terms of adherence to supreme values.
} 
In an unethical society, the weak benefit from propagation of the myth that they are indolent and prefer not to work because they are better-off when the strong believe that they are lazy or the weak are also better-off if the strong believe that, when the weak work, the weak are unproductive.

In contrast, in ethical societies, individuals do not benefit from a reputation for personal laziness, and society is better-off the more productive its members are.

Rather than a spontaneous change of heart by the strong ${ }^{11}$ or favorable responses to external pressure, reasons of self-interest might lead the strong to change their behavior. The selfinterest can arise from a belief by the strong that democracy is imminent, or when the strong benefit sufficiently from tax-financed public expenditures.

\section{NIETZSCHEAN SocIETY}

\section{A. Anarchy}

We begin the examination of the Nietzschean society with a description of the Hobbesian prisoners' dilemma (see Hobbes [1651] 1979). In Table 1, the rule of law is absent and two identical persons face the choice of how to use their resources (time, effort, and initiative). They can each decide whether to use resources only for productive purposes, or to use resources in an attempt to take the other's output. ${ }^{12}$

The first value in Table 1 is the payoff or return to person 1, and the second value is the payoff or return to person 2 . The values of the payoffs are related through

$$
\begin{aligned}
& s>c>a>w \\
& 2 c>a+w
\end{aligned}
$$

Table 1 includes representative values that satisfy the relations in (1).

Wealth is maximized in the Pareto-efficient outcome $(c, c)$, where both persons cooperate in not attempting to appropriate and use all of their resources productively. The dominant strategy for each individual is however to seek to appropriate the output of the other, and the unique Nash equilibrium is $(a, a)$. This outcome is inferior to $(c, c)$ for society at large and for each person individually. The society is therefore poorer than it would be, if a credible commitment were made to mutually respect the right of ownership.

\footnotetext{
${ }^{11}$ See Kuran (1998) for a description of economic behavior in relation to conscience, see Grossman and Kim (2000) for a description of a society that undergoes spontaneous moral revival.

12 The natural right of possession can be determined through the justice of the original acquisition; see Robert Nozick (1973). Skaperdas (1992) provides an analysis of behavior under anarchy. Charles Rowley (2001) compares Hobbes with alternative views of human behavior.
} 
Asymmetry is introduced should one person choose to live according to an ethical code and respect the other's right of possession. The ethical person then has $w$ and the other $s$, and the outcome is materially disadvantageous for the person who behaves ethically.

\section{B. Nietzschean Society}

The source of asymmetry in a Nietzschean society is in terms of strong and weak. It is inconsequential whether the weak are ethical because the weak cannot take from the strong.

We shall identify strong and weak in terms of personal resource availability. Let us denote by $R$ the total output of the strong when the strong use their resources productively, and by $r$ the total output of the weak when the weak correspondingly also use their resources for productive purposes alone. The strong have more resources, reflected in

$$
R>r
$$

We shall see, however, that the direction of the inequality in (2) is not of consequence, and that the weak could be defined as having more productive resources or higher productivity. The basis for the distinction between strong and weak is that the strong can with impunity choose to appropriate the output of the weak. The strength of the strong may be only in that they have no conscience.

The weak face the decision whether to use their resources for production. Should they choose not to use all their resources productively, they nonetheless produce a subsistence output $a$ and have leisure $h$, which together provide them with utility

$$
b=a+h
$$

The weak can always achieve $b$ by choosing not to work beyond their subsistence needs.

The strong confront the decision whether to use all their resources for production, or to use a part to attempt to take from the weak. If the strong choose to take from the weak, they leave the weak with subsistence consumption. In their decision to attempt to appropriate, the strong commit resources $V$ to appropriation, before they know whether the weak will choose to be productive, and therefore before knowing if there is anything to appropriate.

We can think in terms of an agrarian society where the strong arrive at the fields of the weak with the intention to appropriate above-subsistence output. The weak may or may not have chosen to plant and harvest. If there is a crop to appropriate, the return of the strong is

$$
A=(R-V)+(r-a)
$$


If there is no crop to appropriate, the strong have expended $V$ in vain and have a return

$$
B=R-V
$$

Table 2 describes the Nietzschean game.

For the strong,

$$
A>R>B
$$

The best outcome for the strong is a return $A$ where they choose to appropriate and the weak have produced output for them to appropriate. Their worst outcome is the return $B$ when they expend resources for appropriation but the weak choose not to produce beyond subsistence needs. The strong can achieve $R$ unilaterally, by deciding not to attempt appropriate output from the weak.

For the weak,

$$
r>b>a
$$

The weak obtain their best outcome $r$ when they work and keep what they produce. Their worst outcome $a$ arises if they work and their above-subsistence output is appropriated. They can unilaterally achieve $b$ by not producing above their subsistence needs.

The game in Table 2 has no Nash equilibrium in pure strategies. This is also confirmed by the illustrative values.

At $(r, R)$ all resources in the society are used productively. Income distribution is unequal, because of differences in resource ownership or productivity. Over time, the weak can make investments in themselves and their children. Through such investments, and through outcomes where some of the previous wealthy do not succeed in preserving or increasing inherited wealth, there can be social mobility.

$(r, R)$ is however not an equilibrium. Because $A>R$, the strong gain by taking the output of the weak. The outcome then moves to $(a, A)$. The weak have become poorer and the strong have become richer. Total income in the society also declines, since

$$
A+a<R+r
$$

$(a, A)$ is not an equilibrium. Because $b>a$, the weak can improve their situation by not working above subsistence. The outcome then moves to $(b, B)$, where the weak withdraw to live at subsistence levels with leisure or free time. 
$(b, B)$ is also not an equilibrium. Because $R>B$, the strong are better-off using all their resources productively. The outcome consequently moves to $(b, R)$.

Nor however is $(b, R)$ an equilibrium. Because $r>b$, the weak are better-off being productive, which returns the outcome to $(r, R)$. The weak have now once more made themselves prey for the strong, and the cycle begins again.

\section{Mixed-Strategy Equilibrium}

In the absence of equilibrium in pure strategies, we can consider equilibria in mixed strategies. To characterize mixed-strategy equilibria, let the weak work with probability $\mathrm{P}_{\mathrm{w}}$ and the strong appropriate the output of the weak with probability $\mathrm{P}_{\mathrm{s}}$.

Consider first the behavior of the strong. In a mixed-strategy equilibrium, the strong are indifferent about the alternatives of using all resources productively or using resources to attempt to take from the weak. If the strong decide to appropriate, their expected utility is

$$
\left.E U^{\text {strong }} \text { (strong appropriate }\right)=P_{w} A+\left(1-P_{w}\right) B
$$

Should the strong decide to use all their resources productively, they obtain the return with a certainty of $R$.

The mixed strategy of the strong is therefore the solution to

$$
P_{w} A+\left(1-P_{w}\right) B=R
$$

which can be solved for

$$
P_{w}^{*}=\frac{R-B}{A-B}
$$

Now consider the weak. If the weak decide to be productive, their expected utility is

$$
E U^{\text {weak }}(\text { weak work })=P_{s} a+\left(1-P_{s}\right) r
$$

The weak receive $b$ with certainty if they choose not to produce above subsistence.

The weak are therefore indifferent between working and not working above subsistence when

$$
P_{s} a+\left(1-P_{s}\right) r=b
$$


which implies

$$
P_{s}^{*}=\frac{r-b}{r-a}
$$

The mixed-strategy equilibrium is described by the probabilities in (11) and (14). The weak randomize their decision on whether to work according to (11), and the strong randomize their decision on whether to attempt to appropriate according to (14). ${ }^{13}$

\section{Interpretation of the Equilibrium in Terms of Risk}

The above equilibrium can be interpreted in terms of risk. By making productive use of their resources and not attempting to appropriate, the strong obtain $R$ with certainty. Or they can choose to make a risky outlay $V$ in the attempt to appropriate. The decision to attempt appropriation yields $A$ if the weak choose to work and $B$ if the weak choose not to work. As $A$ approaches $R$ (see Figure 1), the expected gain from attempting appropriation approaches zero, and a decision to appropriate becomes less worthwhile, given the risk confronted by the strong that the weak will not work. The equilibrium strategy of the weak reflects this risk. We can express (11) as

$$
P_{w}^{*}=\frac{\left[\frac{R}{A}-\frac{B}{A}\right]}{\left[I-\frac{B}{A}\right]}
$$

Figure 1 confirms that the value of $R / A$ reflects the risk confronting the strong.

Normalizing so that $A=1$ and $B=0$,

$$
P_{w}^{*}=\frac{R}{A}
$$

After normalization, the probability that the weak will work reflects the risk confronting the strong. The likelihood that the weak will choose to work increases as the decision of the strong to attempt to appropriate becomes riskier.

\footnotetext{
${ }^{13}$ For the illustrative values of Table 3 , the mixed-strategy equilibrium is that the weak choose to work with probability 0.375 and the strong choose to appropriate the output of the weak with probability 0.75 .
} 
A similar relation is expressed between the risk confronting the weak and the probability that the strong will choose to attempt appropriation. Normalizing so that $r=l$ and $a=0$, the equilibrium strategy (14) is

$$
P_{s}^{*}=1-b
$$

The probability that the strong will choose to be productive is therefore

$$
I-P_{s}^{*}=b
$$

The probability that the strong will choose to be productive is thus precisely the normalized value of $b$. It is riskier for the strong to attempt appropriation as (normalized) $b$ approaches 1 -or correspondingly, as we see in Figure 2 without normalization, as $b$ approaches $r$.

$b$ is the benefit the weak can obtain with certainty by not working above subsistence. If $b$ and $r$ were equal, the weak would obtain the same benefit if they worked and their output were not appropriated, as when they did not work. If they work, however, they open themselves to the risk of appropriation. Working and taking this risk becomes less worthwhile as $b$ approaches $r .^{14}$

As $b$ increases in value, the likelihood that the weak will produce output to appropriate declines, and the likelihood that the strong will choose to be productive increases.

\section{ECONOMIC SUbVERSIONS}

\section{A. Adverse Consequences of Greater Productiveness}

We now consider the economic implications of Nietzschean behavior.

Let us define the surplus over subsistence produced by the weak when the weak are productive as

$$
r-a \equiv s
$$

Because

$$
\begin{aligned}
& A-B=r-a \\
& R-B=V
\end{aligned}
$$

\footnotetext{
${ }^{14}$ At the other limit where $b=O$ (or non-normalized $b=a$ ), the weak have nothing to lose if their output is appropriated. Without utility from leisure, they obtain $a$ if they work and their output is are appropriated or even if they do not work.
} 
we can express the equilibrium probability that the weak will work as

$$
P_{w}^{*}=\frac{V}{r-a}=\frac{V}{s}
$$

and the equilibrium probability that the strong are productive and will not attempt to appropriate as

$$
I-P_{s}^{*}=\frac{h}{r-a}=\frac{h}{s}
$$

We recall that $V$ is the resource cost of attempting appropriation and $h$ is the utility the weak obtain by not working. We see in (17) that the likelihood that the weak will work increases with the strong's cost of appropriation $V$ - which is understandable - and increases with subsistence consumption $s$, which is also understandable, because this is the output that the weak are assured that they can keep.

The two sources of inefficiency in the Nietzschean society are (1) that the weak may choose not to work, and (2) that resources are diverted from productive activity when the strong attempt to appropriate. We observe that the greater the likelihood for the weak to be productive (the greater is $r$ ), the smaller the likelihood in (17) that the weak will work, and the greater the likelihood in (18) that the strong will expend resources in appropriation. The probability of inefficiency from both sources is therefore increased when the weak are more productive. Hence:

- The productiveness of a population, which is a virtue in an ethical society, is a source of inefficiency in a Nietzschean society.

\section{B. Subterfuge and Parasites}

We see from (18) that the probability the strong will not appropriate increases with the utility the weak derive from leisure. Therefore:

- The weak have an incentive through subterfuge to convince the strong that they are lazy and enjoy leisure.

Successful subterfuge would lead the strong to believe the myth that the weak are lazy.

This compares with other circumstances where people choose not to be productive. For example, Buchanan (1975a) describes the interaction between a charitable person (or donor) and a person whom he describes as a "parasite." The parasite prefers to live off the charity of others rather than be self-reliant. Buchanan's model is shown in Table 3; outcomes are 
ranked from most preferred (4) to least preferred (1); the first value ranks outcomes for the donor and the second value ranks outcomes for the recipient.

The least preferred outcome for both the donor and the "parasite" is (S,s) where the parasite does not work and receives no charity. A better outcome for both the donor and the parasite is $(U, u)$, where the parasite works and the donor provides no charity. The parasite and the donor, however, are making decisions contrary to their nature.

The dominant strategy for the donor is to give. Knowing this, the parasite can choose $(D, h)$, which is a Nash equilibrium. The donor is, however, disappointed in the behavior of the parasite because he prefers the outcome $(H, d)$, where charity supplements self-reliance.

Buchanan presents a picture where lazy people do not work because of misplaced benevolence. In a Nietzschean society, people who do not work (or who do not work consistently) are not parasites encouraged to be lazy by misplaced benevolence, but merely the weak confronting the strong. A Nietzschean society is more efficient if the weak can convince the strong that they are parasites and by nature derive utility from being idle.

\section{The UNEqual Burden of Social INefFiciency}

The society is, of course, worse off in the Nash equilibrium than when all resources are used productively. Let us now consider the distribution of the burden of the inefficiency in the Nash equilibrium. We shall see that the distribution of the burden is quite unequal, and falls entirely on the weak

The expected utility of the weak in the Nash equilibrium is

$$
\begin{aligned}
E U^{\text {weak }} & =P_{w}^{*} P_{s}^{*} a+P_{w}^{*}\left(1-P_{s}^{*}\right) r+\left(1-P_{w}^{*}\right) P_{s}^{*} b+\left(1-P_{w}^{*}\right)\left(1-P_{s}^{*}\right) b \\
& =P_{w}^{*}\left[r-P_{s}^{*}(r-a)\right]+\left(1-P_{w}^{*}\right) b \\
& =b
\end{aligned}
$$

The expected utility of the strong is

$$
\begin{aligned}
E U^{\text {strang }} & =P_{w}^{*} P_{s}^{*} A+P_{w}^{*}\left(1-P_{s}^{*}\right) R+\left(1-P_{w}^{*}\right) P_{s}^{*} B+\left(1-P_{w}^{*}\right)\left(1-P_{s}^{*}\right) R \\
& =P_{s}^{*}\left[P_{w}^{*}(A-B)+B\right]+\left(1-P_{s}^{*}\right) R \\
& =R
\end{aligned}
$$

The expected total welfare of society in the inefficient Nash equilibrium is therefore

$$
E W=R+b
$$


which is less than the total welfare when all resources are used productively,

$$
Y \equiv R+r
$$

We observe, from (19)-(22), that the entire burden of the inefficiency of the Nash equilibrium $(r-b)$ is borne by the weak.

Inefficiency borne by the strong cannot, of course, be part of an equilibrium outcome. The strong would take measures to end inefficiencies that affected them adversely.

It follows that:

- Because the strong are unaffected by the inefficiencies of the Nash equilibrium, they have no personal incentive to implement a program to correct the source of the inefficiencies, and a policy dialogue aimed at reforms cannot be expected to be effective.

\section{REPEATED ENCOUNTERS}

Interactions between the strong and the weak are repeated over time. What can we expect from repeated encounters?

Let us suppose that, with repeated encounters, the weak announce that they are prepared to work, but that they will never again work if their output is ever appropriated. Appropriation "triggers" withdrawal of the weak to the behavior of the Nash equilibrium.

If the strong respond to this announcement by appropriating, they receive $A$. Thereafter, the society is in the Nietzschean (Nash) equilibrium, where the strong have an expected return, $R$.

If we define

$$
\delta=\frac{1}{1+\rho}
$$

where $\rho$ is the discount rate expressing the time preference of the strong, then

$$
I-\delta=\frac{1}{1+\frac{l}{\rho}}
$$

is positively related to the discount rate $\rho$. We shall use this relation to express the discount rate in terms of the value of $(1-\delta)$. 
If the strong appropriate in period one, the present value of their utility is

$$
\Pi_{\text {take }}^{\text {strong }}=A+\frac{\delta}{1-\delta} R
$$

If, on the other hand, the strong respect the rights of the weak in period one (and thereafter), the present value of their utility is

$$
\Pi_{\text {respeect }}^{\text {strong }}=\frac{R}{1-\delta}
$$

With the discount rate zero or positive, because $A>R,(23)$ exceeds (24), and the strong therefore have no incentive to respect the rights of the weak in return for the weak committing to work.

A change in the behavior of the weak, from being productive to the Nash equilibrium, cannot harm the strong because the expected utility of the strong in the Nash equilibrium is the potential maximal value $R$ of their own output. The threat by the weak that appropriation will trigger indefinite withdrawal of their productive effort is therefore an empty one.

We can now summarize the circumstances that we can expect to observe.

- The weak attempt to give the appearance of enjoying laziness and indolence.

- When the weak do work, they wish the strong to believe that they are unproductive.

- The weak bear the entire cost of economic inefficiency and are, on average, poor, and income distribution is unequal.

- The strong have no interest in economic efficiency, and so have no interest in programs of corrective policies.

\section{SeLf-INTERest Of THE Strong In the Rights Of THE WeAK?}

The above conclusions are pessimistic. More optimistic appraisals require identifying new circumstances that lead the strong to want to respect the rights of the weak.

We shall not include spontaneous change by the strong from Nietzschean to ethical behavior. We remain within Nietzschean principles and seek reasons why the Nietzschean strong might change their behavior out of self-interest.

Nothing in the circumstances of a single encounter can lead the strong to wish to change their behavior. We therefore continue with the circumstances of repeated encounters. 


\section{A. Democracy and Majority Voting}

Democracy is inconsistent with the Nietzschean principle that the strong are destined by nature to do as they wish to the weak. The strong may, however, perceive the imminence of future democracy. In the face of perceived political change, the strong have an interest in the rule of law and the assurance of respect for rights of ownership. For, if the strong are the minority, they are vulnerable to appropriation by the weak through voting by the majority. ${ }^{15}$

The interest in the assurance of the rights of ownership is therefore more pressing for the strong than that for the weak. Rather than seek protection of the rights of ownership, the weak may favor re-distribution of the property of the strong or commonality of property.

The weak are, however, protected when the strong make a commitment to rights of private ownership - although under future majority voting the weak may no longer be weak. Because of the interest of the strong in pre-empting appropriation of their own property, society thereby escapes the inefficient Nietzschean equilibrium

Democracy and majority voting need not, however, be sufficient to assure that the strong respect the rights of the weak-the strong can be the majority. ${ }^{16}$

\section{B. Benefits from the Tax Base}

The tax base is more extensive when the weak are productive and provide taxable income. In an efficient equilibrium where both the strong and the weak are productive, an income tax at a proportional rate $T$ provides total taxes of

$$
G^{E}=T(R+r)
$$

In an inefficient equilibrium, the weak have no surplus that can be taxed. Their expected private Nash return $b$ consists of subsistence consumption and utility from leisure (or utility derived from the satisfaction of having nothing that can be appropriated) ${ }^{17}$ In the inefficient mixed-strategy Nietzschean equilibrium, total expected taxes are therefore

$$
G^{N}=T R
$$

\footnotetext{
${ }^{15}$ See for example Breyer and Ursprung (1998) on the possibilities and limitations of appropriation through majority voting.

${ }^{16}$ A Nietzschean society was initiated in Germany in 1933 under democracy and majority voting.

${ }^{17}$ Because taxation in the Nash equilibrium leaves the weak with less than subsistence consumption, the situation of the weak is intolerable: they either die of starvation, or they rebel (see Grossman, 1991).
} 
The expanded tax base in (25) compared to (26) is a source of gain for the strong through benefits from tax-financed public expenditures. That is, the strong gain by having the weak share in the financing of public expenditures.

In repeated encounters, the present value of the wealth of the strong if they appropriate in the first period is now

$$
\widetilde{\Pi}_{\text {take }}^{\text {strong }}=A+\frac{\delta}{1-\delta} R
$$

In (23a), the strong obtain $A$ from appropriation in the first period, they obtain an expected return of $R$ in each period thereafter, and they alone finance public expenditures.

With the expanded base (25) in the efficient state of society, the present value of the wealth of the strong if they do not appropriate is

$$
\widetilde{\Pi}_{\text {respect }}^{\text {strong }}=\frac{R+r T}{l-\delta}
$$

From (23a) and (24a), the strong choose not to appropriate if

$$
1-\delta<\frac{r T}{\Phi}
$$

where

$$
\Phi \equiv r-a-V>0
$$

is the net transfer from the weak to the strong when the weak work and the strong appropriate. $^{18}$

The threat by the weak to withdraw to the Nash equilibrium is now effective in changing the behavior of the strong, provided the strong place sufficiently great weight on the future- that is, if the discount rate of the strong is sufficiently low to satisfy (27). In (27) the maximum discount rate consistent with the strong choosing to respect the rights of the weak increases with the tax rate. Hence:

- The strong have self-interest in respecting the rights of the weak if benefits to the strong through tax-financed public expenditures are sufficiently great, or the discount rate is sufficiently low.

\footnotetext{
${ }^{18}$ In the calculation of the strong, the transfer $\Phi$ is the immediate gain from appropriation, and the benefits of respecting the weak apply over time through the enlargement of the tax base when the weak produce.
} 
In Figure 3, we correspondingly see that, for a discount rate expressed by $\left(1-\delta^{*}\right)$, the strong have an interest in respecting the rights of the weak when tax rates exceed $T^{*}$.

We also see, in (27), that the more productive are the weak, the higher is the maximum discount rate consistent with the strong choosing not to appropriate. ${ }^{19}$ We therefore change our previous conclusion about adverse consequences of the productiveness of the weak: now, the more productive are the weak, the more expansive is the range of discount rates under which a self-enforcing contract emerges where the strong have an interest in circumstances where the weak are consistently productive. ${ }^{20}$

\section{A Coasean Contract?}

Let us return to circumstances where the strong have no interest in efficiency and no selfenforcing contract emerges. The strong then fare as well in the inefficient equilibrium as in the efficient state of society. There are, however, potential gains that can be shared by all from a transition to efficiency. The gains are expressed in the difference between (21) and (22). The Coase Theorem predicts the emergence of a social contract to realize the sharing of these gains.

The Coasean contract is predicated on the ability of the strong to appropriate. Efficiency requires that the weak pay part of above-subsistence output to the strong in return for working without additional appropriation of their output. The efficient contract is thus predicated on extortion, ${ }^{21}$ but, under the terms of the efficient contract, the dominant strategy of the weak is to be consistently productive.

\footnotetext{
${ }^{19} \operatorname{In}(27)$,
}

$$
\frac{d\left(\frac{r}{\Phi}\right)}{d r}>0
$$

In figure 3 a higher value of $r$ increases the maximal discount rate consistent with the strong choosing to respect the rights of the wealth from $\left(I-\delta^{*}\right)$ to $\left(1-\delta^{* *}\right)$ when the tax rate is maintained at $T^{*}$.

\footnotetext{
${ }^{20}$ Applying the terminology of the late Mancur Olson (2000), the discount rate here determines whether the strong are roving or stationary bandits. Roving bandits have no regard for the benefits of future plunder. Stationary bandits perceive that they will be around to plunder the same people in the future. In the above, we are looking for self-interest not to plunder at all.

${ }^{21}$ See Konrad and Skaperdas (1998).
} 
Historically, there is some evidence of the efficient contract. ${ }^{22}$ There is less evidence in more contemporary Nietzschean societies. There is a contradiction to be overcome that the efficient Coasean contract presumes a designation of property rights and the rule of law to protect the weak, whereas there is no rule of law in a Nietzschean society but only the rule of the strong.

\section{Related ObServations}

\section{A. The Source of Advantage of the Strong}

In introducing the Nietzschean model, we observed that it is not necessary to base the distinction between strong and weak on access to resources. We have subsequently seen that the relation between $R$ and $r$ does not affect equilibrium outcomes. The strong may just as well have access to fewer resources and may appropriate because they have an advantage in the use of force, ${ }^{23}$ or perhaps their lack of conscience may the source of the advantage of the strong.

\section{B. Enslavement and Disrespect for Life}

The strong might coerce the weak to work. Coercion has been observed historically in slavery and serfdom, and also in more recent times in enslavement and forced labor. This paper has not considered coercion and enslavement.

\section{Marx}

Karl Marx observed societies with poverty and inequality, and, in response, developed a theory based on exploitation and class antagonism (Marx [1887] 1967). Marx proposed the solution of collectivization of property. Marx differed from Nietzsche in that he recognized concepts of good, evil, and social conscience. Marx sought to end to exploitation, but the system that sought to apply his ideas gave rise to its own version of exploitation of the weak by the strong (see von Hayek, 1944).

\footnotetext{
${ }^{22}$ The patricians (the weak?) paid off the plebeians through the bread and circuses of Rome. Alexander the Great spared any city that opened its gates to him, and the Mongols likewise spared any people that did not resist their authority. There is also evidence of the efficient contract in the contingent release of serfs in $19^{\text {th }}$ century Russia, and in Shariah or Muslim law that allows Jews and Christians to engage in productive activity subject to payment of a special tax. There was often a parallel to Shariah in pre-enlightenment Christian domains.

${ }^{23}$ See also Hirshleifer (1992) on the "paradox of power."
} 


\section{SUMmARY AND IMPLiCATIONS}

Nietzschean behavior is undesirable from an ethical viewpoint. This paper has considered the economic consequences of Nietzschean behavior.

Nietzschean principles have been shown to subvert productive incentives. Productiveness is transformed into a source of inefficiency; the less productive are the weak, the more likely are both the strong and weak to apply their abilities productively. People also benefit from a reputation for idleness.

Incentives to implement change are also adverse. Because the weak alone bear the costs of inefficiency, the strong have no incentive to introduce efficiency-enhancing change, and the society remains under the rule of the strong, and not the rule of law.

More specific predictions are that, when the strong have low discount rates, we expect to see tax-financed social infrastructure; but when discount rates are high, we expect to see the strong taking their gains disproportionately in private consumption and personal capital accumulation. The weak, at the same time, are sporadically and not consistently productive, and propagate the views that they enjoy leisure rather than effort and that they are not particularly productive when they do work. There is therefore broad poverty in the midst of selective and privileged plenty.

When improvement is sought in a policy dialogue, we may therefore be told that "this society is poor because the people here are lazy; they do not like to work; and, when they do sometimes work, they are not very productive." The strong in authority will also claim that there is little point in implementing efficiency-enhancing policy proposals.

A belief in the imminence of democracy, or the potential benefits from a broad tax base, can give the strong an interest in the constitutional protection of individual rights. ${ }^{24}$ When these circumstances are not present, Nietzschean behavior yields pessimistic conclusions about economic progress. The pessimism is consistent with entrenched poverty and inequality in various countries despite decades of assistance by international agencies and donors.

Numerous impediments can stand in the way of exit from entrenched poverty. The conclusion from this paper is that ending entrenched poverty requires recognition of the role of ethics in governance. In particular, we should ask whether behavior of the strong toward the weak is consistent with necessary preconditions for successful development.

\footnotetext{
${ }^{24}$ See Umbeck (1981), Wärneryd (1993), and Hirshleifer (1995) for alternative views on the emergence of self-interest in the respect for property rights. Buchanan (1975b) suggests the need to defer constitutional protection beyond the reach of the time horizon of the self-interest of the strong. See also Brennan and Buchanan (1985).
} 
Table 1. Anarchy

\begin{tabular}{lcc}
\hline & \multicolumn{2}{c}{ Person 2 } \\
\cline { 2 - 3 } & $\begin{array}{c}\text { Uses Resources for } \\
\text { Production Alone }\end{array}$ & $\begin{array}{c}\text { Attempts to } \\
\text { Appropriate Output }\end{array}$ \\
\hline $\begin{array}{l}\text { Person 1 } \\
\text { only produces }\end{array}$ & $c, c$ & $w, s$ \\
Person 1 & $(10,10)$ & $(2.13)$ \\
seeks to appropriate output & $s, w$ & $a, a(4,4)$ \\
\hline
\end{tabular}

Table 2. The Nietzschian Game

\begin{tabular}{lcc}
\hline & $\begin{array}{c}\text { Person 2 } \\
\text { Seeks to } \\
\text { Appropriate }\end{array}$ & $\begin{array}{c}\text { Person 2 } \\
\text { Uses Only Resources } \\
\text { Productively }\end{array}$ \\
\hline $\begin{array}{l}\text { Person 1 } \\
\text { uses resources productively }\end{array}$ & $\begin{array}{c}a, A \\
(2,25)\end{array}$ & $\begin{array}{c}r, R \\
(10,20)\end{array}$ \\
$\begin{array}{l}\text { Person 1 } \\
\text { does not work beyond subsistence }\end{array}$ & $b, B$ & $b, R$ \\
& $(4,17)$ & $(4,20)$ \\
\hline
\end{tabular}

Table 3. The Samaritan's Dilemma

\begin{tabular}{lcc}
\hline & Donor Gives & Donor Does Not Give \\
\hline Parasite works & $H, h(3,4)$ & $U, u(2,2)$ \\
Parasite does not work & $D, h(4,3)$ & $S, s(1,1)$ \\
\hline
\end{tabular}

Source: Buchanan (1975a).

Notes: $s, S=$ sad; $u, U$ unhappy; $d, D=$ disappointed; $h, H=$ happy 
Figure 1: The Risk Confronting the Strong

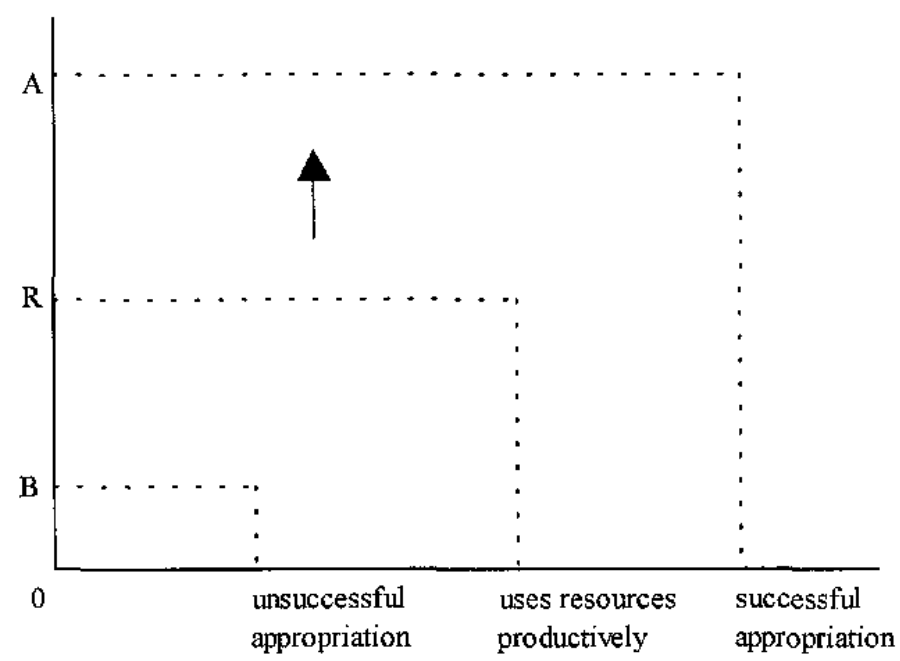

Figure 2: The Risk Confronting the Weak

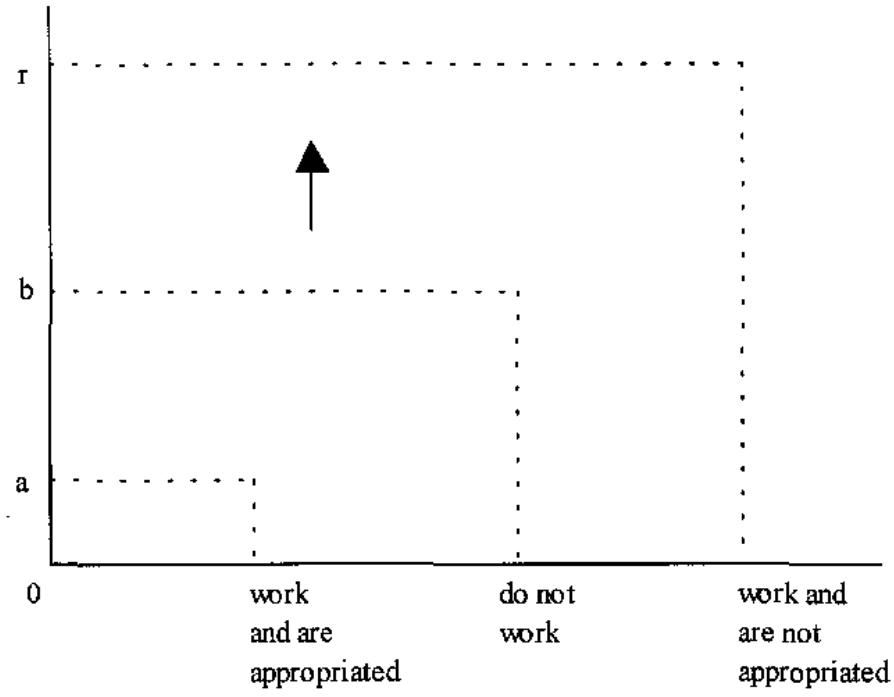


Figure 3: The Discount Rate of the Strong

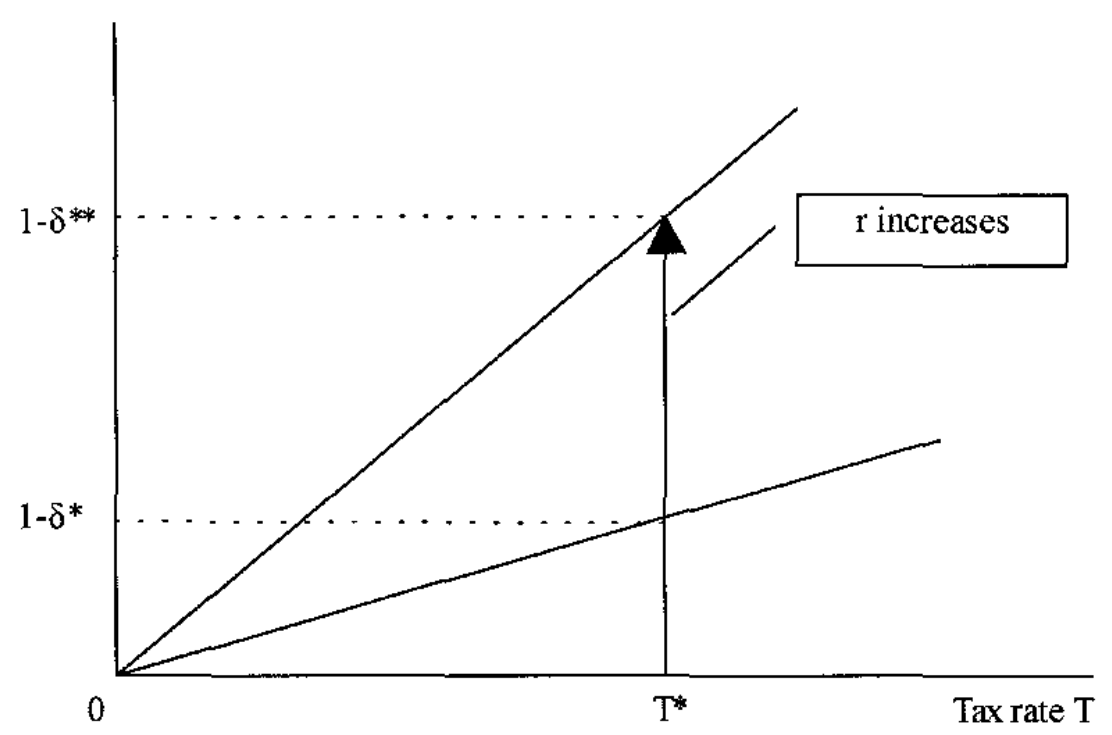




\section{REFERENCES}

Bernholz, Peter, 1993, "Necessary Conditions for Totalitarianism, Supreme Values, Power, and Personal Interest, in Government: Servant or Master, ed. by G. Radnitzsky and H. Boullion (Amsterdam and Atlanta: Rodopi), pp. 267-312.

Breyer, Friedrich and Heinrich W. Ursprung, 1998, "Are the Rich Too Rich to be Expropriated? Economic Power and the Feasibility of Constitutional Limits to Redistribution," Public Choice, Vol. 94 (January), pp. 135-56.

Buchanan, James. M., 1975a, "The Samaritan's Dilemma," in Altruism, Morality and Economic Theory, ed. by E. Phelps (New York: Russell Sage).

— 1975b, The Limits of Liberty: Between Anarchy and Leviathan (Chicago: University of Chicago Press).

Brennan, Geoffrey, and James Buchanan, 1985, The Reason of Rules: Constitutional Political Economy (Cambridge, United Kingdom; New York: Cambridge University Press).

Cassing, James H., 2000, "Economic Policy and Political Culture in Indonesia," European Journal of Political Economy, Vol. 16 (March), pp. 159-71.

Chambers, Robert, 1983, Rural Development: Putting the Last First (London; New York: Longman).

Chu, Ke-young, Hamid Davoodi, and Sanjeev Gupta, 2000, "Income Distribution and Tax and Government Social Spending Policies in Developing Countries," IMF Working Paper 00/62 (Washington: International Monetary Fund).

Diamond, Jared, 1997, Guns, Steel \& Germs: The Fates of Human Societies (New York: W.W. Norton and Company).

Eggertsson, Thráinn, forthcoming, "Norms in Economics: With Special Reference to Economic Development," in Michael Hechter and Karl-Dieter Opp, Social Norms (New York: Russell Sage).

Gallup, John Luke, and Jeffrey D. Sachs, with Andrew D. Mellinger, 1998, "Geography and Economic Development," in Annual World Bank Conference on Development Economics, ed. by Boris Pleskovic and Joseph E. Stiglitz (Washington: World Bank). 
Gelb, Alan, Arye L. Hillman, and Heinrich W. Ursprung, 1998, "Why the Exit from Transition is Prolonged," in Economic Interdependence and Cooperation in Europe, ed. by Nicholas C. Baltas, George Demopoulos, and Joseph Hassid (Berlin; New York: Springer-Verlag).

Grossman, Herschel I., 1991, "A General Equilibrium Model of Insurrections," American Economic Review, Vol. 81 (September), pp. 912-21.

— and Minseong Kim, 1995, "Swords or Plowshares? A Theory of the Security of Claims to Property," Journal of Political Economy, Vol. 103 (December), pp. $1275-88$.

— 2000, "Predators, Moral Decay, and Moral Revivals," European Journal of Political Economy, Vol. 16 (June), pp. 173-87.

Hall, Robert E., and Charles I. Jones, 1999, "Why do Some Countries Produce So Much More Output Per Worker Than Others?" Quarterly Journal of Economics, Vol. 114 (February), pp. 83-116.

Havrylyshyn, Oleh, 1995, "How Patriarchs and Rent-Seekers are Hijacking the Transition to a Market Economy," Perspectives on Contemporary Ukraine, Vol. 2 (May-June) pp.1-6.

Hayek, Friedrich August von, [1944] 1994, The Road to Serfdom (Chicago: University of Chicago Press, $4^{\text {th }}$ ed.).

Hillman, Arye L., 1998, "Political Economy and Political Correctness," Public Choice, Vol. 96 (September), pp. 219-39.

- and Otto Swank, 2000, "Why Political Culture Should be in the Lexicon of Economics," European Journal of Political Economy, Vol. 16 (March), pp. 1-4.

Hirshleifer, Jack, 1991, “The Paradox of Power," Economics and Politics, Vol. 3, (November) pp.177-200.

— 1995, "Anarchy and its Breakdown," Journal of Political Economy, Vol. 103 (February), pp. 26-52.

Hobbes, Thomas, [1651] 1974, Leviathan (New York: Dutton)

Konrad, Kai A., and Stergios Skaperdas, 1998, "Extortion," Economica, Vol. 65 (November), pp. 461-77. 
Krugman, Paul, 1998, "The Role of Geography in Development," in Annual World Bank Conference on Development Economics, ed. by Boris Pleskovic and Joseph E. Stiglitz (Washington: World Bank).

Kuran, Timur, 1998, "Moral Overload and its Alleviation," Economics, Values, and Organization, ed. by Avner Ben-Nur and Louis Putterman (Cambridge, United Kingdom; New York: Cambridge University Press), pp. 231-66.

Landes, David S., 1998, The Wealth and Poverty of Nations: Why Some Are So Rich and Some are So Poor (New York: W.W. Norton).

Levin, Mark, and Georgy Satarov, 2000, "Corruption and Institutions in Russia," European Journal of Political Economy, Vol. 16 (March), pp.113-132.

Marx, Karl, [1887] 1967, Capital: A Critique of Political Economy, ed. by Frederick Engels, translated from the third German edition by Samuel Moore and Edward Aveling (New York: International Publishers).

McGuire, Martin C., and Mancur Olson, Jr., 1996, "The Economics of Autocracy and Majority Rule: The Invisible Hand and the use of Force," Journal of Economic Literature, Vol. 34 (March), pp. 72-96.

Milanovic, Branko, 2000, “The Median-Voter Hypothesis, Income Inequality, and Income Distribution: An Empirical Test with the Required Data," European Journal of Political Economy, Vol. 16 (September), pp. 367-410.

Nietzsche, Friedrich Wilhelm, [1886] 1997, Beyond Good and Evil: Prelude to a Philosophy of the Future (Mineola, New York: Dover Publications).

Nozick, Robert, [1973] 1993, "Distributive Justice" in Social Choice Theory, Vol. 3: Social Justice and Classical Liberal Goals, ed. by Charles K. Rowley, Elgar Reference Collection Series, International Library of Critical Writings in Economics, Vol. 27 (Aldershot, United Kingdom: Edward Elgar).

Olson, Mancur, 2000, Power and Prosperity: Outgrowing Communist and Capitalist Dictatorships (New York, New York: Basic Books).

Rowley, Charles K., 2000, "Political Culture and Economic Performance in Sub-Saharan Africa," European Journal of Political Economy, Vol. 16 (March), pp. 133-58.

- 2001, "Constitutional Political Economy and Civil Society," Rules and Reason: Perspectives on Constitutional Political Economy, ed. by Ram Mudambi, Pietro Navarra, and Giuseppe Sobbrio (Cambridge, United Kingdom; New York: Cambridge University Press), pp. 69-96. 
Skaperdas, Stergios, 1992, "Cooperation, Conflict, and Power in the Absence of Property Rights," American Economic Review, Vol. 82 (September), pp. 720-39.

Tanzi, Vito, Ke-young Chu, and Sanjeev Gupta, 1999, eds., Economic Policy and Equity (Washington: International Monetary Fund).

- 2000, Policies, Institutions and the Dark Side of Economics (Cheltenham (United Kingdom) and Northampton, Massachusetts: Edward Elgar).

Treisman, Daniel, 2000, "The Causes of Corruption: A Cross-National Study," Journal of Public Economics, Vol. 76, No. 3, pp. 399-457.

Umbeck, John, 1981, "Might Makes Rights: A Theory of the Foundation and Initial Distribution of Property Rights, Economic Inquiry, Vol. 19 (January), pp. 38-59.

Wärneryd, Karl, 1993, "Anarchy, Uncertainty, and the Emergence of Property Rights," Economics and Politics, Vol. 5 (March), pp. 1-14. 